\title{
Comparison of nutrition knowledge in patients with type 1 and type 2 diabetes
}

\author{
Edyta Łuszczki ${ }^{1,2}$, Katarzyna Dereń1, Grzegorz Sobek ${ }^{1}$ \\ ${ }^{1}$ Medical Faculty, University of Rzeszow, Poland \\ 2 Faculty of Public Health, Medical University of Silesia, Katowice, Poland \\ Łuszczki E, Dereń K, Sobek G. Comparison of nutrition knowledge in patients with type 1 and type 2 diabetes. J Pre-Clin Clin Res. 2015; \\ 9(1): 23-26. doi: 10.5604/18982395.1157571
}

\begin{abstract}
Introduction. Diabetes as a non-infectious chronic metabolic disease is a problem of the contemporary world, including Poland. Behaviour therapy plays an important role in its treatment, i.e. proper diet and regular physical activity. Patient's knowledge of nutrition principles is also an essential complement to the treatment, reducing the risk of late complications of diabetes.

Objective. Assessment of the nutrition knowledge of patients with type 1 and type 2 diabetes.

Materials and method. The study involved 300 randomly selected patients from Rzeszów and the surrounding area (135 patients with type 1 diabetes and 165 patients with type 2 diabetes) aged 8-78.The analysis was made using a survey questionnaire prepared by the authors of the study, conducted in the period July - December 2011.

Results. The survey revealed that patients with type 1 diabetes have greater nutrition knowledge and knowledge about diabetes than patients with type 2 diabetes. On the other hand, they are less likely to comply with the recommendations of the diet prescribed by a doctor or a dietician.

Conclusions. Patients with diabetes, regardless of age, type of diabetes, gender, or disease duration require continuous broadening of diabetes knowledge. Systematic training will teach patients proper eating habits related to their diet and lifestyle.
\end{abstract}

\section{Key words}

diabetes, nutrition knowledge

\section{INTRODUCTION}

More than 20 years ago, the St. Vincent Declaration was adopted by the World Health Organization and the International Diabetes Federation, stating that diabetes is a major and growing health problem in Europe. Therefore, governments should create conditions to minimize the losses resulting from complications of the disease [1].

According to the World Health Organization, diabetes is a group of metabolic diseases, characterized by chronic hyperglycaemia due to defective secretion and /or insulin action. It has been recognized by the United Nations as a non-infectious epidemic of the $21^{\text {st }}$ century [2].

In 2010, the number of people worldwide affected by diabetes was estimated at about 300 million. The latest data of the International Diabetes Federation (IDF) of 14 November 2014, show that diabetes currently affects as many as 387 million people worldwide, which indicates a very rapid increase in the illness. The IDF indicates that by the year 2035, the number of patients will have risen to over 592 million [3]. Among the reasons for such a high incidence, genetic predisposition should be mentioned as well as inappropriate nutrition, insufficient amount of activity and a steadily ageing population [4].

The situation in Poland looks equally dramatic. It has been estimated that 2.5 million people are affected by the disease, whereas in 750,000 patients the disease has not yet been diagnosed [5].

Address for correspondence: Edyta Łuszczki, Medical Faculty University of Rzeszów, Warszawska 26a, 35-205 Rzeszów, Poland

E-mail: edyta.luszczki@gmail.com

Received: 29 October 2014; accepted: 02 June 2015
Studies clearly indicate that early diagnosis of diabetes, proper patients' education by diet, physical activity, and early treatment implementation reduce the costs connected with diabetes because they prevent or delay the occurrence of complications. This is very important because type 2 diabetes shortens life expectancy by 5-10 years, and in $50 \%$ of patients, at least one complication appears before the disease has been diagnosed [6].

\section{OBJECTIVE}

To assess the knowledge of nutrition principles in diabetes and their compatibility with the recommendations of the diet with a limited amount of easily digestible carbohydrates in patients from Rzeszów and the surrounding area.

\section{MATERIALS AND METHOD}

The study involved 300 patients suffering from type 1 or type 2 Diabetes selected by simple randomization. The analysis of the nutrition knowledge was made on the basis of a survey questionnaire prepared by the authors of the study. Participation in the study was anonymous and voluntary, carried out from July - December 2011. The questions regarding weight and height allowed to calculation of the Quetelet index -the body mass index (Body Mass Index = body weight $[\mathrm{kg}] /$ height $[\mathrm{m}]^{2}$, and compare its value with the recommendations of the WHO experts (> 18.5 - underweight, from 18.5-24.9 - normal weight, from 25-29.9 - overweight, $>30$ obesity) [7]. 
The level of nutrition knowledge was determined by a scale included in the survey questionnaire. It consisted of 8 questions concerning the nutrition knowledge, with one correct answer. The questions concerned, among others, the glycaemic index, carbohydrate exchanges, or fibre. $6-8$ points (frequency $=0.75-1$ ) obtained in the survey was considered high knowledge; $4-5$ (frequency $=0.5-0.63$ ) average knowledge, and below 4 (frequency $=0.13-0.38$ ) low nutrition knowledge.

The tested group consisted of 135 people with type 1 diabetes and 165people with type 2 diabetes - 141 female and 195 male respondents. The average age of male respondents was 47 and female respondents 40 .

The obtained results were evaluated statistically using Statistica 10.0 and Microsoft Office Excel 2007. For statistical analysis of the obtained results, the Chi 2 test was applied for qualitative variables, and Cramer's $\mathrm{V}$ coefficient to measure the strength of the relationship between the variables. The level of significance $p=0.05$ indicated the existence or nonexistence of statistically significant correlations between the studied traits.

\section{RESULTS}

In the presented group of patients suffering from diabetes, their knowledge about nutrition was analyzed. 135 patients suffered from type 1 diabetes, which accounted for $45 \%$, while 165 patients suffered from type 2 diabetes (55\%) (Fig. 1, 2). The average body mass index BMI was 24.8 in females and 27.5 in males (Fig. 5).

Approximately $73 \%$ of the respondents had a diet prescribed by a doctor or a dietician, whereas $26.6 \%$ of them had not been instructed in any way. Among the patients with type 1 diabetes, the division was equal: $50 \%$ had a prescribed diet, and the other $50 \%$ did not. A much larger number of patients with type 2 diabetes (92\%) received recommendations from a doctor or a dietician concerning their diet.

Among the patients with a prescribed diet $(n=220)$, $65.9 \%$ of them complied with its recommendations, more patients $(67.8 \%)$ with type 2 diabetes than with type 1 diabetes $(61.8 \%)$.

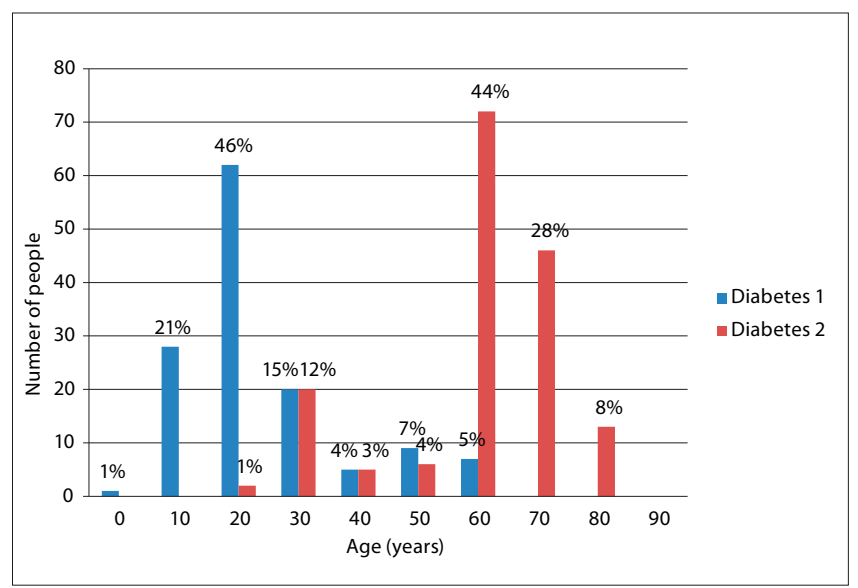

Figure 1. Division of tested group of patients suffering from diabetes by age

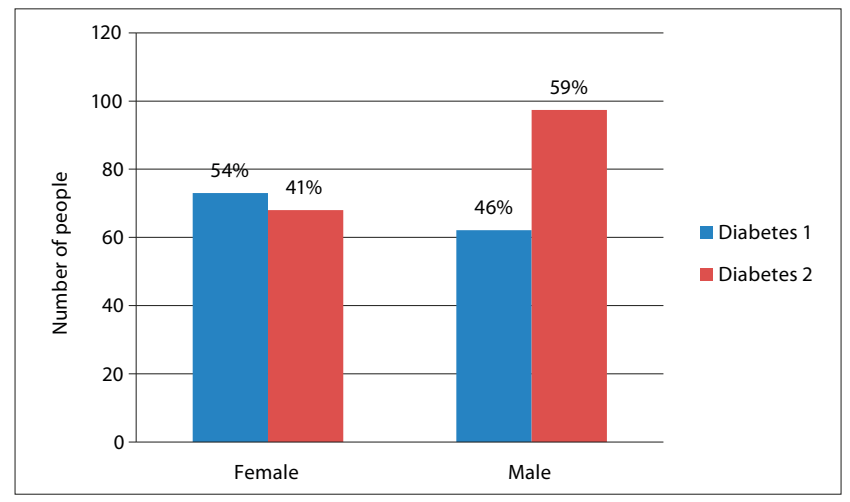

Figure 2. Division of tested group of patients suffering from diabetes by gender

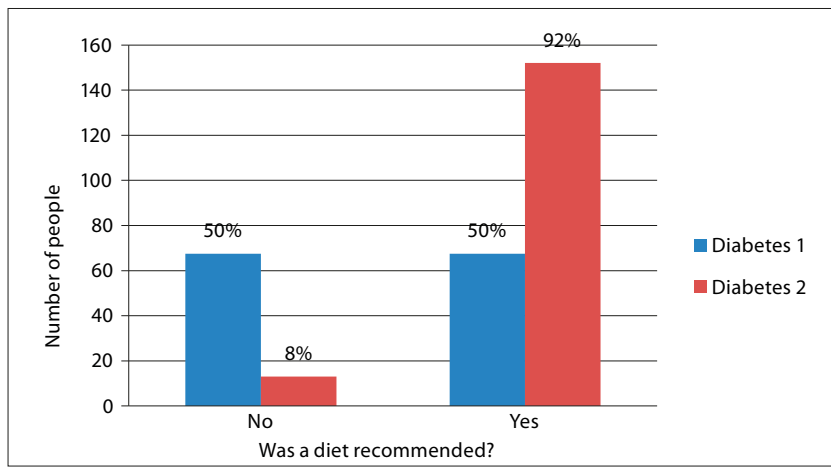

Figure 3. Diet with limited amount of easily digestible carbohydrates prescribed by doctor or dietician according to type of diabetes

Table 1. Adherence of respondents to recommended diet with limited amount of easily digestible carbohydrates

\begin{tabular}{lcc}
\hline Dietary adherence & Diabetes 1 & Diabetes 2 \\
\hline YES & $61.8 \%(n=42)$ & $67.8 \%(n=103)$ \\
\hline NO & $38.2 \%(n=26)$ & $32.2 \%(n=49)$ \\
\hline TOTAL & $100 \%(n=68)$ & $100 \%(n=152)$ \\
\hline
\end{tabular}

$13.3 \%$ of respondents assessed their knowledge about nutrition very well, $60.3 \%$ assessed it well, $24.7 \%$ had poor knowledge, whereas $1.7 \%$ had no such knowledge (Fig. 4).

Every fifth patient with type 1 diabetes declared that they had very good knowledge about their diet, and almost threequarters $(69.6 \%)$ that their knowledge was good. Only $6.7 \%$ assessed their knowledge as poor or (3.7\%) did not have such knowledge.

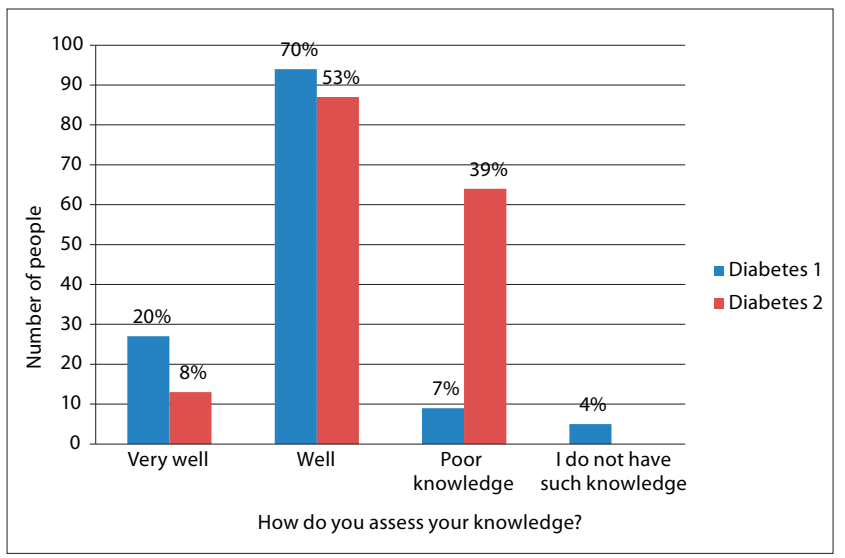

Figure 4. Respondents' self-assessment concerning their knowledge about nutrition in diabetes 
Among the patients with type 2 diabetes only $7.9 \%$ evaluated their knowledge very well, more than a half $(53.3 \%)$ well, whereas almost $38.8 \%$ stated they had poor knowledge.

A statistically significant correlation was noted in the analysis of the variable type of diabetes, and the recommended diet (moderate correlation, Cramer's V coefficient 0.43; $\mathrm{p}=10^{-5}$ ), assessment of their knowledge about nutrition (low correlation, Cramer's V coefficient 0.34; $\mathrm{p}=10^{-5}$ ) and BMI (moderate correlation, Cramer's Vcoefficient0.53; $\mathrm{p}=10^{-4}$ ).

Poor correlation was also noted between a random variable of BMI, and a prescribed diet (Cramer's V coefficient 0.29; $\left.\mathrm{p}=10^{-5}\right)$.

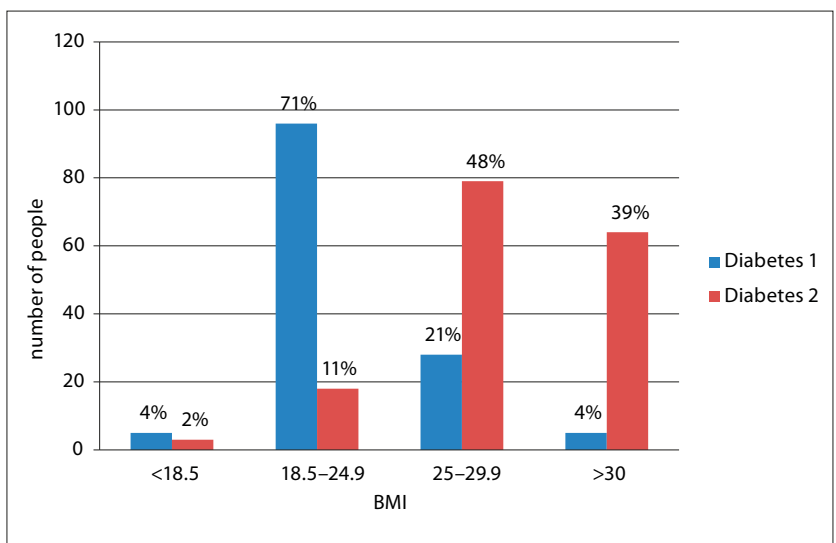

Figure 5. Body mass index (BMI) value of respondents

Nutrition knowledge. The average number of points obtained in the nutrition knowledge level survey was 5 points. More points were obtained by the patients with type 1 diabetes $(n=135)$, with a score of 5.5 points. Patients with type 2 diabetes $(n=165)$ scored 4.6 points. The results obtained from the survey showed that $48.9 \%(n=66)$ of patients with type 1 diabetes and $29.1 \%(n=48)$ of patients with type 2 diabetes had a high level of nutrition knowledge. Average level of knowledge was stated by $42.2 \%(n=57)$ of patients with type 1 diabetes and $49.1 \%(n=81)$ of patients with type 2 diabetes. More patients with type 2 diabetes $(21.8 \%$, $n=36)$ than with type 1 diabetes $(8.9 \% n=12)$ had a low level of knowledge (Fig. 6).

A statistically significant correlation was shown between random variable type of diabetes and random variable level of knowledge in the examined overall population $(\mathrm{p}=0.04)$ - low correlation force (Cramer's V coefficient $=0.14$ ).

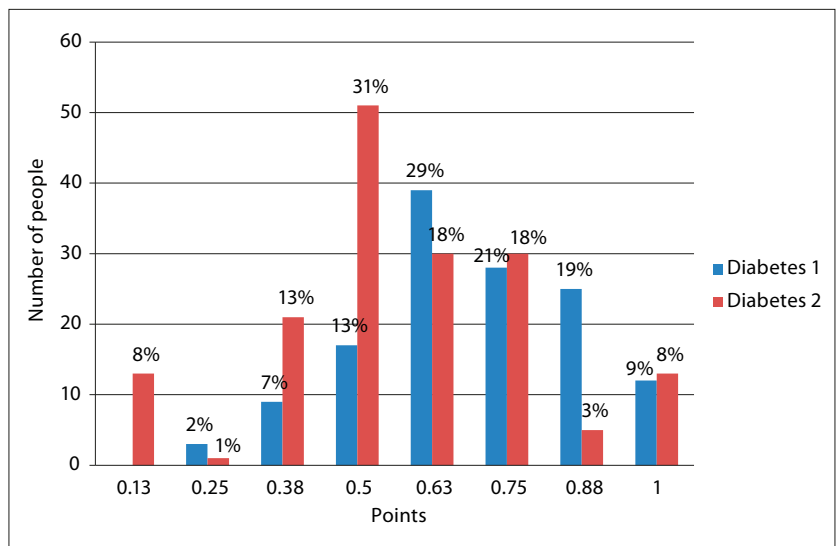

Figure 6. Frequencies of correct answers concerning nutrition among patients with diabetes

\section{DISCUSSION}

The specificity of the group of patients with diabetes is the subject of many studies, both in terms of new methods of treatment, genetic susceptibility to the disease, as well as in terms of nutrition habits, nutrition knowledge, or lifestyle of the patients $[8,9]$.

Behaviour therapy involving the use of proper diet and regular physical activity plays an important role in the treatment of carbohydrate metabolism disorders. Adherence to the basic principles in the treatment of diabetes retards progression of the disease and the number of complications; it also delays the need for the application of insulin therapy and oral hypoglycaemic drugs $[10,11]$.

The aim of the study was to assess the nutrition knowledge of patients with type 1 and type 2 diabetes. The respondents were selected from the city of Rzeszów and the surrounding area. At the same time, on the basis of the survey questionnaire, the patients' body mass and height were assessed, which allowed calculation of the body mass index (BMI), on the basis of which the occurrence of underweight, ideal body weight, overweight or obesity were assessed.

The conducted study confirmed the presence of excess body mass in the group of males, the weight reduction would foster the improvement of glucose tolerance [12].

In the survey questionnaire respondents were asked whether they had a diet prescribed by a doctor or a dietician, and if they complied with the recommendations. General practitioners (GPs) generally treat diabetes with a diet or physical activity. According to the World Health Organization (WHO), in the United States, adherence to nutritional recommendations and exercise plans is far below the optimal value and concerns respectively $52-70 \%$ and $26-52 \%$ of patients [13]. In Mexico, the figures are 38\% and $25 \%$. In the DAWN study involving more than 2,000 patients from 13 countries (including 9 from Europe), the implementation of nutrition recommendations and physical activity amounted to $37 \%$ and $35 \%$ [15]. In Poland, a study involving 118 respondents, conducted in the Pomeranian Medical University in Szczecin, showed that among patients who considered their knowledge about diet as sufficient, $44.4 \%$ complied with their diet recommendations, while $55.5 \%$ did not. Among those who did not think that their knowledge was sufficient $21.7 \%$ used a diet, and $78.2 \%$ did not [16].

Among factors affecting good implementation of recommendations by patients, the importance of knowledge about diabetes, its effects and proper knowledge about nutrition, are emphasized. The patient's doctor or dietician should explain the goals and effective ways of carrying out suggested treatment. It is essential to simplify the therapy to the maximum and reduce the amount of prescribed medicines $[17,18]$. Education of the patients also aims to broaden their nutrition knowledge as an essential complement to the treatment. It is also the most effective and the simplest method of preventing complications. Joslin, the creator of modern diabetology in the year 1919, stated: 'the patient who knows the most, lives the longest' [19].

In 1980, the World Health Organization officially recommended officially regarded the education of patients with diabetes, regardless of the disease type, as an essential element of therapy. It also noted that it is a necessary part of the process of the social integration of this group of patients 
[20]. The results of research conducted by the Diabetes Control and Complications Trial (DCCT) and the United Kingdom Prospective Diabetes Study (UKPDS) proved unequivocally that improvement of glycaemic control reduces the risk of development and progression of chronic complications of diabetes $[21,22]$.

Health education aims to prepare patients for their active participation in the treatment by increasing their knowledge about the disease, motivation to act, teaching practical skills and self-control behaviour [23]. Broadening knowledge about proper nutrition in diabetes lowers the risk of later complications which are major causes of disability and death. Targets should be set, such as preventing complications, informing patients with diabetes about the possibility of a high quality of life and complete mental and physical fitness, in spite of some limitations [24, 25].

The results concerning the nutrition knowledge of patients with diabetes, obtained on the basis of the survey questionnaire by the authors of the presented study, are similar to the results obtained by other authors, and indicate the necessity for improving the nutrition knowledge of patients with diabetes. Patients should be prepared to participate actively in the treatment of diabetes, they should be taught self-monitoring and glycaemic control with a proper diet.

\section{RESULTS}

On the basis of the obtained results the following conclusions can be formulated:

1. Patients with type 2 diabetes more frequently had a diet recommended by a doctor or dietician than patients with type 1 diabetes.

2. More patients with type 1 diabetes than type 2 diabetes complied with the diet recommendations.

3. Patients with type 1 diabetes had a higher level of nutrition knowledge.

\section{REFERENCES}

1.Pietrzykowska E, Zozulińska D, Wierusz-Wysocka B. Jakość życia chorych na cukrzycę. Pol Merk Lek. 2007; 23: 311-314 (in Polish).

2. Kinalska I. Otyłość a cukrzyca - problemy terapeutyczne. Przegl Kardiodiabetol. 2008; 3(4): 296-301 (in Polish).

3.International Diabetes Federation. IDF Diabetes Atlas update poster, 6th edn. Brussels, Belgium: International Diabetes Federation, 2014.

4. Jarosz-Chobot P, Otto-Buczkowska E. Epidemiologia cukrzycy typu 1. Przegl Pedriatr. 2009; 39(4): 229-234 (in Polish).

5. Wittek A, Strojek K, Grzeszczak W. Prevalence of diabetes and cardiovascular risk factor in industrial area in Southern Poland. Exp Clin Endocrinol Diabetes. 2009; 117: 350-353.
6. Currie CJ, Kraus D, Morgan CL, Gill L, Stott NC, Peters JR. NHS acute sector expenditure for diabetes: the present, future, and excess in-patient cost of care. Diabet Med. 1997; 14: 686-692.

7. Tatoń J, Kuczerowski R, Kowrach M. Kliniczna charakterystyka zespołu metabolicznego. Przew Lek. 2003; 6(4): 58-65 (in Polish).

8. Czech A, Cypryk K, Czupryniak L, et al. Zalecenia kliniczne dotyczące postępowania u chorych na cukrzycę, Stanowisko Polskiego Towarzystwa Diabetologicznego. Diabetologia Kliniczna 2013; 2 (supl. A): A1-A70 (in Polish).

9. American Diabetes Association: Standards of medical care in Diabetes 2013. Diabetes Care 2006; 29: 2140-2157.

10. Cheetin CC, Sharps SJ, Wexler DJ, et al. Dietary Intake ofEicosapentaenoic and Docosahexaenoic Acid and Diabetic Nephropathy: Cohort Analysis of the Diabetes Control and Complications Trial. Diabetes Care 2010; 33: 1454-1456.

11. Jarosz M, Kłosiewicz-Latoszek L. Cukrzyca: zapobieganie i leczenie. Warszawa, PZWL, 2007 (in Polish).

12.Zielke M, Reguła J. Sposób żywienia i aktywność fizyczna a wskaźniki antropometryczne chorych na cukrzycę typu 2. Żyw Człow Metab. 2007; 34: 1131-1137 (in Polish).

13. Kogan AJ. Overcoming obstacles to effective care of type 2 diabetes. Am J Manag Care. 2009; 15: 255-262.

14. Hernández-Ronquillo L, Téllez-Zenteno JF, Garduńo-Espinoza J, González-Acevez E. Factors associated with therapy noncompliance in type-2 diabetes patients. Salud. Publica Mex. 2003; 45: 191-197.

15. Peyrot M, Rubin RR, Lauritzen T, et al. Resistance to insulin therapy among patients and providers results of the cross- -national Diabetes Attitudes, Wishes, and Needs (DAWN) study. Diabetes Care 2005; 28 , 2673-2679.

16. Karakiewicz B, et al. Znaczenie edukacji zdrowotnej w pracy z pacjentem z cukrzycą typu 2. Ann UMCS. 2004; 59, 14: 449-455 (in Polish).

17. Dailey G, Kim MS, Lian JF. Patient compliance and persistence with anti hyperglycemic therapy: evaluation of a population of type 2 diabetic patients. J Inter Med Res. 2002; 30: 71-79.

18. Dezii CM, Kawabata H, Tran M. Effects of once-daily and twice-daily dosing on adherence with prescribet glipizide oral therapy for type 2 diabetes. South Med J. 2002; 95: 68-71.

19. Kahn CR, Weir GC, King GL, et al. Joslin's Diabetes Mellitus. Ed. 14th. Lippincott Williams \& Wilkins, 2004: 597-610.

20. WHO Expert Committee on Diabetes Mellitus. Education. Second report. World Health Organ Tech Rep Ser. 1980; 646: 1-80.

21. The Diabetes Control and Complications Trial Research Group. The effect of intensive treatment of diabetes on the development and progression of long-term complications in insulin-dependent diabetes mellitus. N Engl J Med. 1993; 329: 977-986.

22. UK Prospective Diabetes Study (UKPDS) Group. Intensive bloodglucose control with sulphonylureas or insulin compared with conventional treatment and risk of complications in patients with type 2 diabetes (UKPDS 33). Lancet 1998; 352: 837-853.

23. Stumvoll M, Goldstein BJ, van Haeften TW. Type 2 diabetes: principles of pathogenesis and therapy. Lancet 2005; 365: 1333-1346.

24. Johnson ST, Bell GJ, MCcargar LJ, Welsh RS, Bell RC. Improved cardiovascular health following a progressive walking and dietary intervention for type 2 diabetes. Diabetes Obes Metab. 2009; 11: 836843.

25. Gutschall MP, Miller CK, Mitchell DC, Lawrence FR. A randomized behavioral trial targeting glycemic index improves dietary, weight and metabolic outcomes in patients with type 2 diabetes. Public Health Nutr. 2009; 23: 1-9. 